\title{
THE EXCITEMENT OF DOING / TRANSLATING SCIENCE: EMOTIVITY IN POLISH AND ENGLISH RESEARCH ARTICLES AND POPULAR SCIENCE TEXTS
}

\begin{abstract}
There has been little research in emotiveness in academic discourse (see e.g. Bednarek 2008, Łyda 2013) and even less attention paid to the problem of 'emotive shifts' in the process of translation. While the former results from the widespread belief in the neutrality and objectivity of science, the latter seems to be derived from the tacit assumption that translators generally tend to preserve the sense of the source language text and that their presence in the translation is marginal and negligible. The present paper addresses both of these issues. It takes as its starting point a cross-linguistic study on emotive markers in Polish and English research articles (Łyda 2013; Łyda 2014), which demonstrates differing patterns in the distribution of these markers in the two languages. Next, it moves to an analysis of emotive markers in a parallel corpus of popular science texts compiled from English popular science journal Scientific American and Polish Wiedza $i$ $\dot{z} y c i e$. The third study concentrates on shifts in the process of translating English emotive markers in Scientific American articles in its Polish edition only to show a tendency of neutralising strong emotion markers in the target text.
\end{abstract}

Key words: academic discourse, emotion, emotive markers, Polish, English, translation

\section{Introduction}

Launched in the early 1980s the research into academic discourse has explored many different dimensions of the language used in a wide range of academic disciplines, offering a variety of answers to the questions about its prominent features. Although many of them have been regarded as characteristic of academic discourse, the claim that they form a set of obligatory markers of academicity of texts would still be unfounded. What remains indisputable, though, is the general belief that scientific research is a quest for truth relying on objective criteria, which, as it is, should also find their place in academic discourse. This view has been persuasively incorporated into a large number of academic writing manuals and academic style guides, thus instilling

\footnotetext{
* Institute of Linguistics, Faculty of Humanities, University of Silesia, ul. Grota-Roweckiego, 41-200 Sosnowiec, Poland; e-mail: andrzej.lyda@us.edu.pl
} 
the conviction in academic novices of the formal, logical, impersonal and unemotional language of scientific research. A notable example is the discussion of persuasion in academic writing, in which Fairbairn and Wynch (2011: 203) advise students to "learn to distinguish persuasion that takes place through the use of tricks or appeals to the emotions, from persuasion that is supported by sound evidence."

The exclusion of emotions as a subjective experience as opposed to the objective criteria on which the scientific quest for truth relies has a long history. Gotti (2012: 103) finds its sources as early as in the seventeenth-century argumentative discourse, which established the norm of reliability, faithfulness and sincerity in scientific reports. In a similar historical account of the academic from medieval up to modern times Clark (2006: 6-7) argues that:

[...] in the modern metaphysics of research, a cool, objective, meritocratic, professional self suppresses the passionately interested, collegially motivated, nepotistic, old-fashioned, traditional academic self.

Finally, the same diagnosis is provided by Thaiss and Myers Zawacki (2006: 6), for whom "in the academic universe the senses and emotions must always be subject to control by reason".

For some thinkers such as Lemke (1990) academic discourse sets a false opposition between the world of scientific fact, impersonal, authoritative and seemingly objective, and the personal world with its inaccuracies, uncertainties and interests. The consequences of this opposition are clearly presented in Duszak (1997: 12), who in her severe criticism of the idea of the separation of the human from the academic, warns that if "the organization of a research text is supposed to take place 'above' and 'beyond' the writing ego", this would lower the interpersonal meanings and "limit its interactive abilities." Others, for example Campbell (1975: 404) in the now classical essay The Personae of Scientific Discourse, question the very possibility of excluding a persona:

[...] to discourse is, before anything else, to act, and the very nature of the act implies an actor; thus when a scientific discourse admits to no concern, no regard for what is studied - especially for persons who are studied - the dramatic or literary critic is likely to perceive that discourse as implying a persona (as every discourse does), but a persona displaying positively and actively the coldness, the disdain, the alienation [...].

For Campbell discourse, including scientific discourse, operates on several levels and its underlying structure consists in the aesthetic or dramatic presentation of selves selected from a variety of selves, which he calls personae. As such, academic writing is not free from the very context in which it comes into being and which 
creates. Although Campbell reduces the space for the writer's individuality in choices dictated by sociopolitical context, what is equally unquestionable is the role of culture in which the selves operate. Culture, after Nostrand (1989) concerns the attitudes and beliefs, ways of thinking, behaving and remembering shared by members of that community. It is in the context of culture so defined with all its do's and don'ts concerning expressing emotions by research article writers that I pose a question whether English and Polish academic texts differ quantitatively and qualitatively in the use of features that show personal involvement or emotion and, if this is the case, whether the potential difference is reflected in English into Polish translation of texts situated on the academic continuum of genres. These are questions that are currently unanswered, and hence explored here.

\section{Emotivity in academic discourse: a literature review}

In spite of a few attempts to address this issue, the problem of emotivity as an aspect of interpersonal meaning in academic discourse had not been extensively examined until recently when the problem of emotion talk received due attention in Bednarek (2008).

Previous references to the concept of emotive meaning were rare and marginal, emotivity being often either alluded to or implied by other notions. One of such notions is that of stance, which according to Hyland (2005), consists of an academic writer's appeals of three types: logos, ethos and pathos. The last of these, i.e. pathos, is constructed through affective appeal including among others means of personal evaluation "expressing surprise, agreement, pleasure, emphasis and so on" (Hyland 2005: 81), as in:

Hopefully these new ventures in a market with tremendous potential will bring more profits to the group. (Ming Pao Daily, 1993) (my bold type, AŁ).

A more explicit mention of emotive lexis in academic writing can be found in Hyland's account of interactional resources (Hyland 2005: 49), which next to hedges, boosters, self mentions and attitude markers, include explicit emotional markers such as sentence adverbs (hopefully) and adjectives (remarkable).

Several other researchers have referred to emotiveness in their account of stance. Biber et al. (1999: 966) define stance as the expression of "personal feelings, attitudes, value judgments, or assessments." This was further developed in Conrad and Biber (2000), who argue for a three-partite composition of stance including the categories of epistemic stance, style stance, and attitudinal stance. And it is in the last of these categories that a direct reference to emotivity can be found as attitudinal stance is said to convey "the speakers' personal attitudes or feelings" (Biber 2000: 57). 
The notion of feeling is mentioned also in Hunston and Thompson (2000: 5) in their analysis of the category of evaluation as "a cover term for the expression of the speaker or writer's attitude or stance towards, viewpoint on, or feeling about the entities or propositions that he or she is talking about".

Finally, more attention is paid to the subject of emotive language in appraisal theory (Martin and White 2005), concerning the expression of the interpersonal aspects of meaning and the attitudinal resources exploited "for modalising, amplifying reacting emotionally (affect), judging morally (judgment) and evaluating aesthetically (appreciation)" (Martin 1995: 28). Affect systems draw on rich resources for describing emotions, both positive and negative, and in English it may take the form of nouns, verbs, adjectives and adverbs (Bednarek 2008; Dziwirek and LewandowskaTomaszczyk 2010). Obviously, other lexical and grammatical means are also available.

Given the rich repertoire of lexical means for the realisation of affect, an obvious question arises why their potential presence in academic texts has not been shown in previous studies. As Precht (2000; referred to in Bednarek 2008: 16) argues, the frequency of occurrence of such expressions in academic was too low for the statistical technique known as factor analysis to detect them in the analysed corpora.

Bednarek (2008) is the first systematic study of expressions denoting affect/ emotion in three discourse types, including an academic written discourse corpus of 6 million words. In her modified version of the appraisal theory affect refers to positive and negative emotions of the speaker and third parties grouped on the basis of three oppositions: in/security - dis/satisfaction - un/happiness.

Last but not least, in considering studies on emotivity in the educational context, the work of Dziwirek and Lewandowska-Tomaszczyk (2010) is not to be forgotten. Their study offers an analysis of emotive terms in a number of corpora, including the PELCRA (Polish-English Language Corpora for Research and Applications) and examines the use of the terms also in the FL classroom.

\section{Emotivity in Polish and English research articles}

\subsection{Objectives}

The major objective is to analyse explicit emotive markers in Polish and English serious and popular science writing and the impact of translation on the preservation of language-specific modes of expressing and naming emotions. Each of the studies presented here prepares the ground for the subsequent study, which analyses the fluctuation of emotive lexis in terms of its quantity and quality. 


\subsection{Materials and procedures}

The collection of materials and the selection of procedures for the three studies presented below followed from the definition of emotions and emotive language adopted here. The existing literature on emotions is very extensive as the problem of the nature of emotions and their classification has been addressed in diverse ways in the field of psychology, sociology, medicine and neuroscience, to name a few. Here emotions are understood after Fiehler (2002: 84) as "a specific procedure for the solution of such tasks of evaluation and statement" in terms of such criteria as expectations, desires, social norms and self-concept. I also accept the well-founded claim that only some portions of the emotional spectrum are lexicalised in languages of distinct cultures, which explains the sources of differences in the number of emotion terms at their disposal.

Emotions as evaluations can be conveyed in a number of ways ranging from behaviours like shuddering to verbal communication by means of expressive emotional talk and denotative emotion talk. This distinction follows from the fact that, as Bamberg (1997: 309) observes, it is natural that the relation between language and emotions can be viewed from two angles either as a relation in which language is 'performed' emotively or where language reflects objects in the world, including emotions. Bednarek (2008: 12) distinguishes between the two concepts and defines them, after Martin and White (2005), as emotional talk expressing emotions and emotion talk comprising linguistic means employed to denote emotions and positioned on a cline of implicitness ranging from the most implicit descriptions of unusual behavior (e.g. He drinks a lot.) to the use of behavioural surge terms (e.g. He smiled.) to the use of most explicit mental disposition terms (e.g. fear), shown in Figure 1:

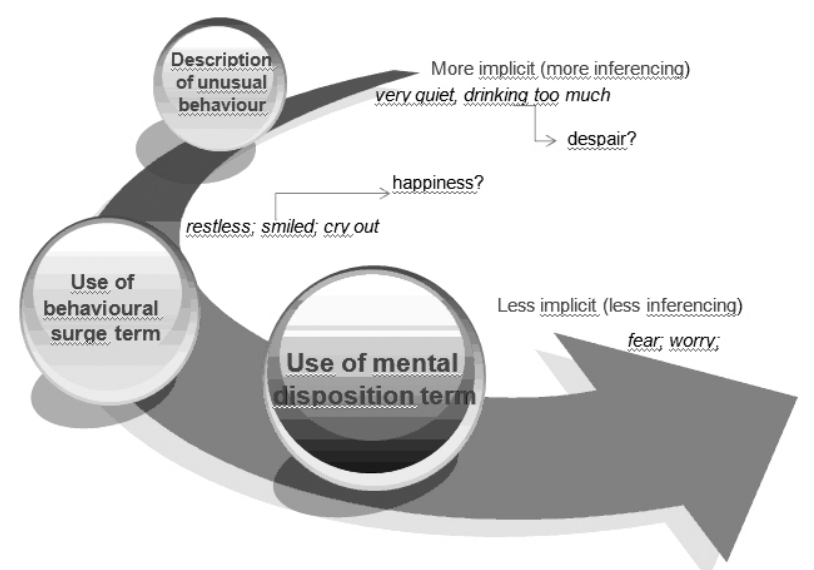

Figure 1. Linguistic means of denoting emotions (adapted from Bednarek 2008) 
For the purposes of the three studies the analysed data were limited to mental disposition terms, i.e. lexical items explicitly naming emotions, e.g. love, grateful, hopefully, etc. Emotional talk and metaphorical expressions were excluded from this analysis.

Even when limited to mental disposition terms, the analysis encountered certain methodological difficulties because it required that the data be analysed according to an established classification of emotions. Considering the fact that there is practically no such generally accepted classification, the decision was made to apply an emotion model proposed by Plutchik and Conte (1997) and Plutchik (2001), shown in Figure 2.

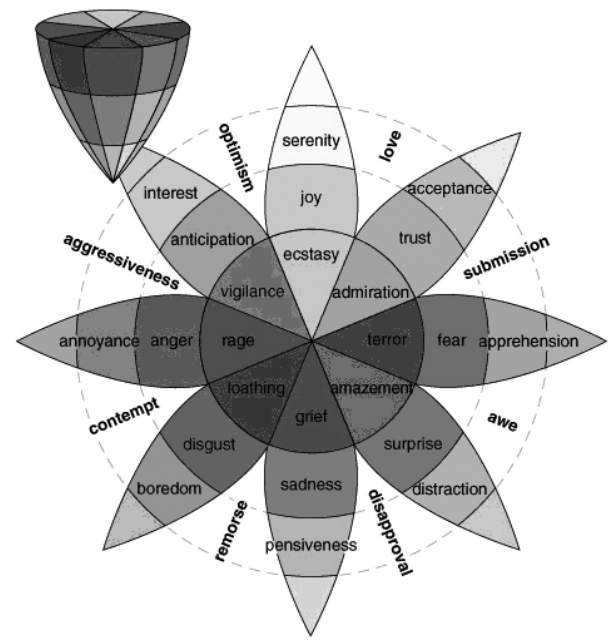

Figure 2. Three-dimensional circumplex model of emotions (after Plutchik 2001)

An advantage of this model lies in the fact the apart from emotions, it represents also the relation between them and their intensity. This circumplex model defines eight primary emotions: anger, fear, sadness, disgust, surprise, anticipation, trust, and joy, and complex emotions resulting from a combination of two basic emotions into a dyad. The dyads are marked in the blank space between basic emotion sections. The inner circle denotes the most intense emotions and the outer circle - the least intense. Each circle sector has an opposite emotion.

\subsection{Study 1: Emotivity in ELANG and POLANG research articles}

Łyda (2014) performed an analysis based on two corpora of research articles (RA) from the domain of language and communication. The English language corpus 
(ELANG) included 200 electronically available research articles published in prestigious international linguistic journals such as, for example, Journal of Pragmatics, Journal of English for Academic Purposes and Language and Communication in the years 2005-2007, obtained from Science Direct, Elsevier's full-text scientific database. The total number of words in the English linguistics corpus was about 2.0 million.

The Polish language corpus (POLANG) also comprised 200 research articles published in journals from the same field, all of them published in the years 2000-2006. The corpus consists of articles from seven journals such as, for example, Acta BalticoSlavica, Biuletyn Polskiego Towarzystwa Językoznawczego, Etnolingwistyka, Język a Kultura and Neofilolog. The total number of words in this corpus approximated 0.91 million.

The exclusion criteria for emotive terms were established as follows: an emotive term was not included in the final list if it was found (1) in a citation from another source, (b) to function as an example, and (c) to function as an operational term in the research reported in RA.

\subsubsection{Results}

The total number of emotion terms identified in the two corpora was 1,332. Their distribution was not equal: ELANG corpus contained 788 emotion terms, whereas POLANG corpus included only 540 occurrences. Given the fact that ELANG had almost twice as many words as POLANG, these figures were normalised in terms of occurrences per million words. The results obtained showed that the frequency of occurrence figures were substantially higher for POLANG than ELANG, approximately 391.37 and 591.88 occurrences per million in ELANG and POLANG corpora, respectively. This indicates that emotion terms in POLANG were over 1.51 times as frequent as in ELANG corpus. However, when the total number of tokens is calculated in terms of the number of 200 articles in each corpus, this proportion is reversed. It amounted to 1.73 with the average 3.94 occurrences of emotive terms in a single ELANG RA and 2.7 in a POLANG RA, which follows from the fact that ELANG articles were usually longer than POLANG.

Figures 3. and 4. present the frequencies of emotion terms broken down per lexical categories and per their intensity in ELANG and POLANG.

The total of 788 occurrences of emotion terms in ELANG was represented by 63 lexical items (types). For POLANG the list contained 59 lexical types. Among most common emotive terms were adjectives interesting (258 tokens) and surprising (66 tokens) in ELANG and interesujacy (108 tokens) and ciekawy (89 tokens) in POLANG. These adjectives accounted for $48 \%$ of all the occurrences of adjectives 
in ELANG and almost $73 \%$ in POLANG. Equally high were also the percentages for adverbs interestingly and surprisingly.

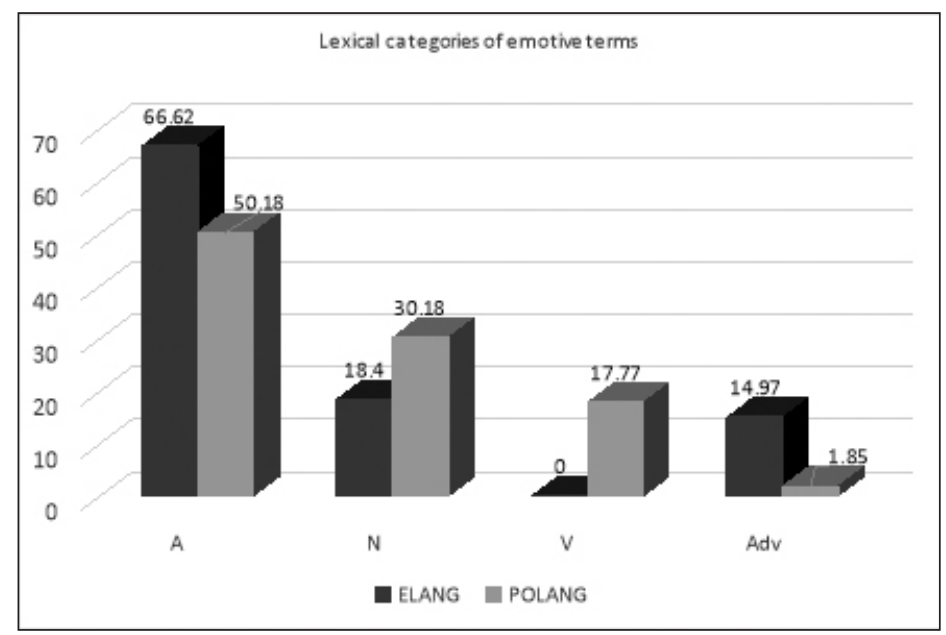

Figure 3. Lexical categories of emotive terms in ELANG and POLANG

With regard to part-of-speech realizations, the most frequently employed category for this corpus were adjectives, at the level of approximately $50-66 \%$. In the case of ELANG this category of emotion terms was followed by four nominal forms represented by such lexemes as consternation, confusion, interest and surprise (145 tokens or $18.40 \%$ ) and adverbial forms (118 tokens or 14.97\%). Thus, these findings are in accordance with the claim that the written register tends to reflect a nominal style, in which nouns and adjectives prevail (Sager et al. 1980 and Biber 2006). Similarly, it is immediately noticeable that also in POLANG there was a strong preference for adjectives, the category of adjectives followed by nouns, verbs and a small group of adverbs.

Interestingly, most of the emotion terms in both corpora viewed at collectively tended to correspond to the outer and the middle circle emotions in Plutchik's model, which is shown in Figure 4.

Generally, emotions in ELANG represented mainly the outer circle of the emotion model (weak emotions). Only $20 \%$ of the emotive terms were derived from the middle circle and an insignificant number from the inner circle of strong emotions. No qualitative differences between the two corpora were found in POLANG, yet in quantitative terms the outer circle emotions were only twice as frequent as the middle circle ones. Also the strong inner circle emotions (mainly joy and fear) were more common in POLANG than in ENLANG. Interesting insights come also from 


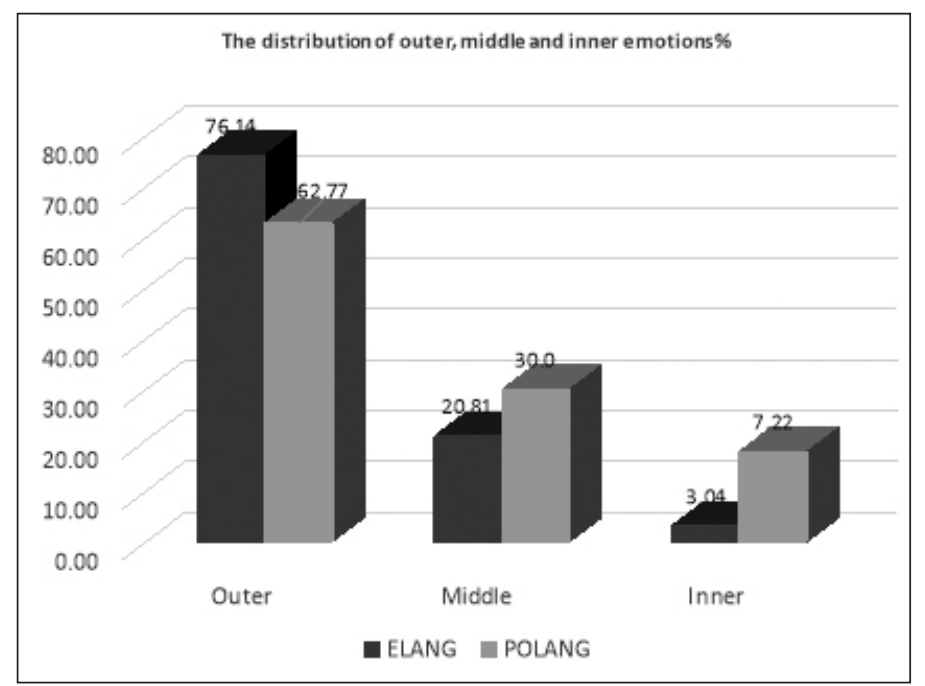

Figure 4. The distribution of emotive terms according to their intensity in ENLANG and POLANG (\%)

the analysis of the middle circle emotions. Again Polish writers tend to use emotion terms denoting middle circle emotions significantly more often than English authors. With all due caution taken with generalizing these findings, it can be concluded that expressions of stronger emotions are more common in Polish than in English RAs.

\subsection{Study 2: Emotivity in Polish and English popular science articles}

\subsubsection{Objectives}

If a research article can be regarded as a prime example of academic discourse, then at the peripheries of the continuum of discourse there lies also popular science discourse, offering insights into the relations between science and society. For de Oliveira and Pagano (2006: 628) the popularization article is "not a simplified version of the research article, but a discursive reconstruction of scientific knowledge to an audience other than the academic one". The characteristic feature of this reconstruction is its subjectivity, as such popular science articles possess properties different from the genre of research article. Discussing the issue of subjectivity and objectivity in academic writing, Myers (2003) argues that while the authors of research papers create objectivity by elimination of people from the account, an opposite phenomenon takes place in the case of popular science because the participants are visible in texts. As a result of this rhetorical operation popular science texts do not give the impression of objective opinion since they are not free of emotional involvement. Considering the 
high interactivity level in popular science texts and the fact that the issue of emotive lexis in such texts had not been studied in literature, an analysis of emotivity in Polish and English popular science magazines was performed using two corpora analysed by Habdas (2014) and recompiled and restructured by the present author.

\subsubsection{Materials and procedures}

The English language corpus (SA) and the Polish corpus (WiZ) consisted of 120 articles, each published in 2009-2012. The articles came from two magazines: American Scientific American (SA) published since 1845 and Polish Wiedza i Życie (WiZ) issued regularly since 1926.

The two corpora were divided into six subcorpora related to six branches of science, each subcorpora comprising 20 articles. The total number of words in SA was 100, 333 and 115, 889 in WiZ. The selection criteria for emotive lexis were the same as in the POLANG/ELANG study.

\subsubsection{Results}

The total number of emotion terms identified in the corpora was 249 for SA and in 172 in WiZ. As the sizes of the two corpora were almost identical, it is clear from these results that SA (English) writers used more emotive terms than Polish popular science authors in WiZ.

The distribution and the share of the emotive terms in each of the analysed branches of science are shown in Figure 5. and 6, with the highest share in Science and Natural Science in SA and Natural Science and Humanities in WiZ.

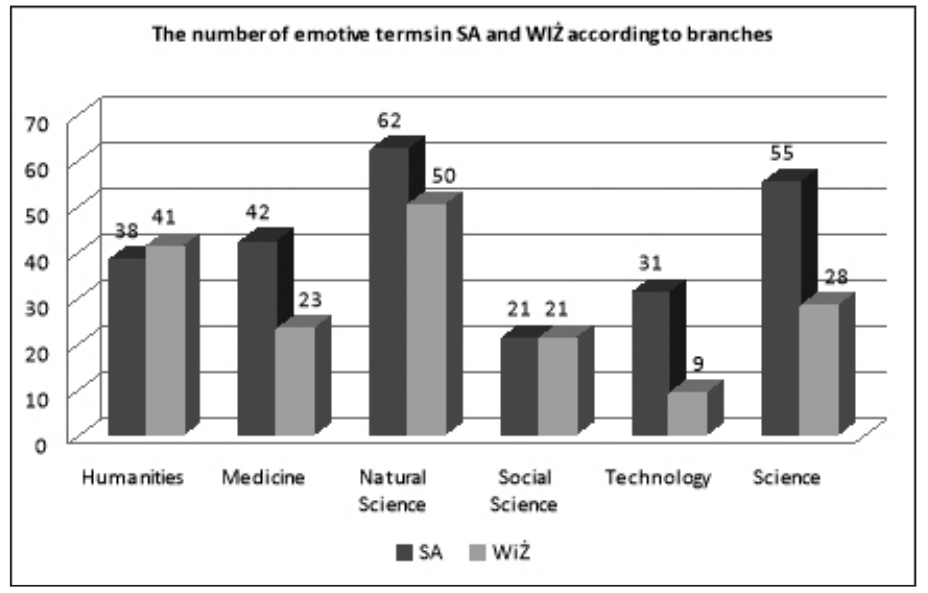

Figure 5. The total number of emotive terms in English SA and Polish WiZ per branch 


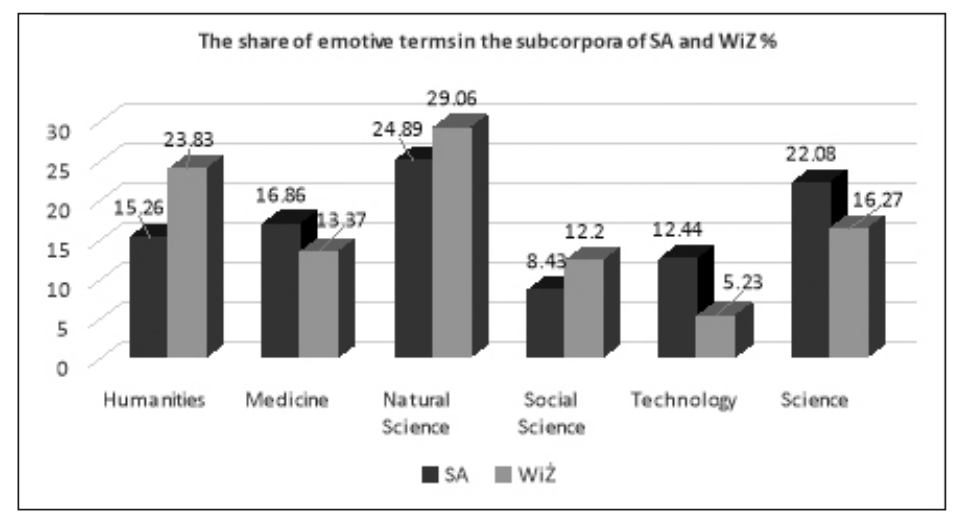

Figure 6. The distribution of emotive terms in English SA and Polish WiZ (\%)

The most interesting results concern the distribution of emotion terms according to their intensity (see Figures 6. and 7). While in serious academic writing (Study 1), the regular quantitative pattern observed was Outer $>$ Middle $>$ Inner, in the case of popular science texts in both corpora middle intensity emotion terms outnumber outer ones.

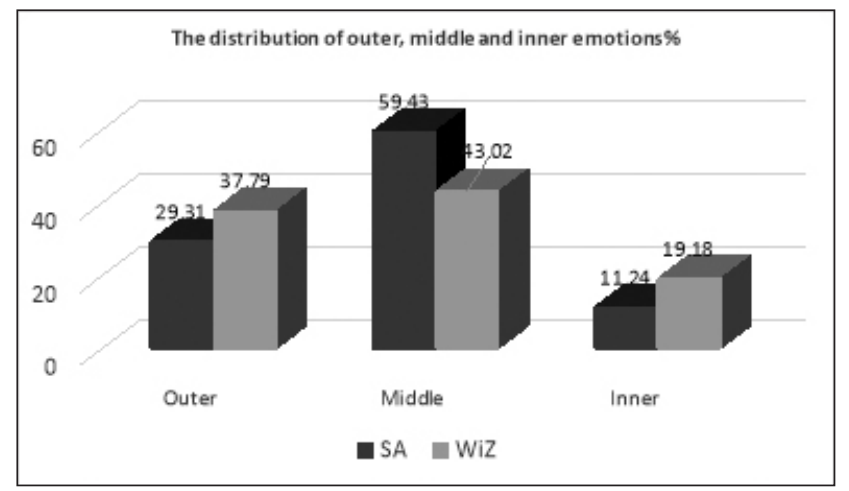

Figure 7. The distribution of emotive terms according to their intensity in SA and WiZ

There was also observed a significant increase of the number of Middle and Inner emotive terms at the expense of Outer ones. Emotions from the middle circle constitute $59.43 \%$ of all emotion terms used by Americans, whereas, in the Polish corpora there are fewer than half as many, namely $43.02 \%$.

Similarly to POLANG/ELANG, Polish popular science writers are still inclined to use strong emotions almost twice as often (19.18\%) as American writers (11.24\%), with almost every fifth emotive term in WiZ belonging to the inner circle. 
These findings allow us to conclude that both Polish and English popular science articles exhibit a higher degree of emotivity than RAs owing to the increased use of emotive terms, most of which represent stronger emotions than RAs.

\subsection{Study 3: Emotivity in translation of American Scientist in Polish Świat Nauki}

\subsubsection{Objectives}

The markedly different picture of the use of explicit emotive terms in popular science writing in Polish and English when compared with serious science writing invites an intriguing question concerning the translation of highly emotive English popular science texts into Polish. It could be hypothesized that given the equally high emotivity of Polish popular science texts, the translation of English popular articles into Polish should not pose a problem in this respect. After all, the general conviction that translation preserves semantic nuances of the source language texts derives from a tacit assumption that translation consists in a simple conversion of information from one language into another. However, holders of this view seem to ignore the fact that translation may serve much different purposes, often determined by such factors as the expected function of the text in the target culture, target language translation policy makers and even the expectations of the readership. In the course of preliminary analysis of the two corpora discussed below evidence derived from a small sample of translations seemed to suggest that the high degree of emotivity in source language texts was actually reduced in the target language. This suggestion was backed up by the evidence gathered by Min-Hsiu Liao (2010), through which the author concludes that the translation strategies of rendering the interactive dimension in popular science writing for the public are not employed systematically. In order to study how emotive terms - which also contribute to the interactivity of texts - are rendered in Polish translation of English popular science articles a study of two corpora was carried out.

\subsubsection{Materials and procedures}

The English language corpus under analysis consisted of the same texts of Scientific American as in the study of SA and WiZ. The Polish one comprised 120 translations of SA articles published in Świat Nauki (SW) - the Polish edition of Scientific American.

\subsubsection{Results}

The total number of emotion terms identified in SA was 249. The figure for Polish amounted to 218 in SN. T, as shown in Figure 8. 


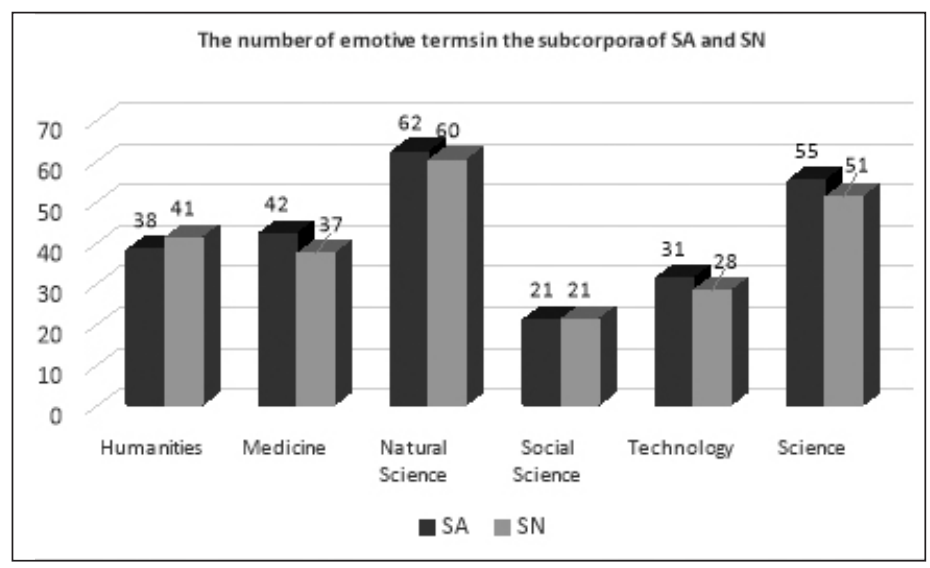

Figure 8. The total number of emotive terms in English SA and Polish SN per branch

It is interesting to note that the total number of emotive terms in SN (238) is lower than in SA (249), which could be interpreted as a result of the decision of Polish translators to resort to the strategy of omission. Actually the situation is even more complex: the emotive terms were omitted 15 times, yet the Polish translators added 4 emotive terms to the SL text. The term omission should be understood as referring to two strategies, i.e. deletion and the use of non-emotive paraphrase/equivalent, as in the following examples from the corpora:

(1) Nevertheless, it is an interesting solution and physicists have wondered about its physical interpretation

Niemniej jednak jest to jakieś rozwiązanie.... (interesting deleted)

(2) [...] interactions among cells, aided by amazing advances in imaging. [...] interakcji międzykomórkowa, wspomagany wielkim postępem w obrazowaniu (amazing rendered as great)

The analysis revealed differences in the distribution of the emotive terms in SN. Quantitatively similar renditions of SA emotive terms can be observed only in the case of Middle circle emotions, where the figure for $\mathrm{SN}$ reaches almost the same value as in SA. Surprisingly, the results for the Outer circle are much higher and for the Inner circle much lower than in the SL articles, as shown in Figure 9. 


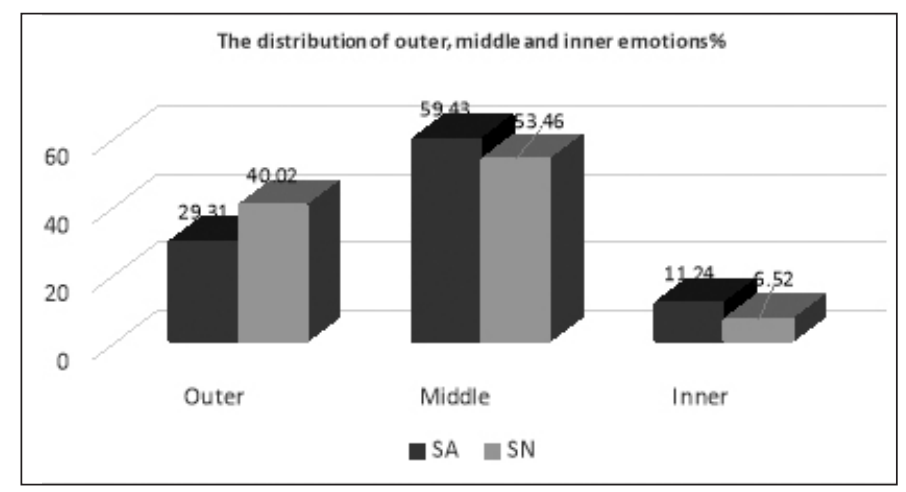

Figure 9. The distribution of emotive terms according to their intensity in SA and SN

This discrepancy follows from the fact that Polish translators produced a number of shifts between these circles of intensity by translating English emotive terms by means of Polish terms denoting weaker emotions, as illustrated below:

(3) Yet amazingly, most people walk around breathing freely without any kind of airway infection.

Zastanawia fakt, że większość z nas spaceruje [...] (a shift from the Inner circle to the Outer circle; amazingly translated into Polish by weaker puzzles)

(4) $[. .$.$] was disappointed and more than a little angry to find prevention or$ treatment

[...]... Sprawiło mi zawód a nawet zmartwiło, gdy znalazłem [...] (a shift from the Middle circle to the Outer circle; angry translated by weaker made sad)

Taken together, these results suggest that Polish translations of emotive terms in English popular science articles tend towards writing typical of research articles rather than popular science. While the distribution pattern that emerged from the analysis of research articles (Study 1) was Outer $>$ Middle $>$ Inner, the pattern identified in the SA and WiZ study (Study 2) gave priority to the Middle circle emotions, followed by the Outer and the Inner One. Although the same pattern was discerned in the SA and SN study (Study 3), the results are somewhat unanticipated given the marked increase in the share of the Middle and Outer circles in SN translations, decreasing the intensity of SA original emotive terms.

Obviously, this strategy of translation consisting in the reduction of the explicit emotivity does not follow from any peculiar requirements established for popular science writing in Poland in general. What is possible is that this practice of neutralising 
emotivity may reflect the SN editors' policy based on different intentions underlying the process of science popularisation. While the informative and educational functions of popular science writing remain the same in $\mathrm{SA}$ and $\mathrm{SN}$, the linguistic forms serving the function of getting the reader involved vary, at least as regards emotive lexis. The shift in intensity levels of emotive terms in serious and popular science writing in the English language magazines are more radical than in the Polish language articles, which - fluctuating as they are - remain relatively more stable in this respect.

This hypothesis is in partial agreement with Min-Hsui Lia (2010), who in her diagnosis of apparent inconsistencies in rendering the same translational problems states that the major factor behind translators' decision is their recognition of the purpose of the SL text. The purpose, as Min-Hsui Liao argues, is very often achieved in the TL by means not necessarily remaining in accord with the SL means. Not defying this explanation, I am inclined to think that the source of translational shifts can be located not only at the level of individual translators, many of whom are scholars themselves and as such may (try to) adhere to the style of serious science writing. An equally possible reason is that both the translators and editors of popular science magazines are aware of the accepted limits of emotivity in Polish science writing, be it serious or popular writing, and they try not to deviate from the norms.

\section{References}

Bamberg, M. (1997). Language, concepts and emotions. The role of language in the construction of emotions. Language Sciences, 19, 309-340.

Bednarek, M. (2008). Emotion Talk and Corpora. Houndsmills: Palgrave MacMillan.

Biber, D., S. Johansson, G. Leech, S. Conrad, E. Finegan (1999). Longman Grammar of Spoken and Written English. Harlow, UK: Pearson.

Biber, D. (2006). University language: A Corpus-based Study of Spoken and Written Registers. Amsterdam: John Benjamins.

Campbell, P. N. (1975). The personae of scientific discourse. Quarterly Journal of Speech, 61(4), 391-405.

Clark, W. (2006). Academic Charisma and the Origins of the Research University. Chicago: University of Chicago Press.

Conrad, S. and D. Biber (2000). Adverbial marking of stance in speech and writing. In: S. Hunston and S. Thompson (eds.), Evaluation in Text: Authorial Stance and the Construction of Discourse, Oxford: Oxford University Press, 56-73.

De Oliveira, J. M. and A. S. Pagano (2006). The research article and the science popularization article: a probabilistic functional grammar perspective on direct discourse representation. Discourse Studies, 8(5), 627-646. 
Duszak. A. (1997). Cross-cultural academic communication: A discourse-community view. In: A. Duszak (ed.), Culture and Styles of Academic Discourse, Berlin: Mouton de Gruyter, 11-39.

Dziwirek, K. and B. Lewandowska-Tomaszczyk (2010). Complex Emotions and Grammatical Mismatches: A Contrastive Corpus-based Study. Berlin and New York: Walter de Gruyter.

Fairbairn, G. and C. Winch (1996). Reading, Writing and Reasoning: A Guide for Students. Oxford: Oxford University Press.

Fiehler, R. (2002). How to do emotions with words: Emotionality in conversations. In: S. R. Fussell (ed.), The Verbal Communication of Emotions: Interdisciplinary Perspectives, Mahwah, New Jersey: Lawrence Erlbaum, 79-106.

Gotti, M. (2012). Managing disputes with civility on seventeenth-century argumentative discourse. In: U. Busse and A. Hubler (eds.), Investigations into the Metacommunicative Lexicon of English: A Contribution to Historical Pragmatics, Amsterdam: John Benjamins, 89-109.

Habdas, A. (2014). Emotion Talk in Polish and American Popular Science Articles. Unpublished M.A. thesis. University of Silesia, Katowice.

Hunston, S. and G. Thompson (eds.). (2000). Evaluation in Text: Authorial Stance and the Construction of Discourse: Authorial Stance and the Construction of Discourse. New York: Oxford University Press.

Hyland, K. (2005). Metadiscourse: Exploring interaction in writing. London and New York: Continuum International Publishing Group.

Hyland, K. (2006). English for Academic Purposes: An Advanced Resource Book. London: Routledge.

Lemke, J. (1990). Talking Science: Language, Learning, and Values. Norwood, NJ: Ablex Publishing Corporation.

Liao, M. H. (2010). Translating science into Chinese: an interactive perspective. The Journal of Specialised Translation, 13, 44-60.

Łyda, A. (2013). Disciplinary cultures and emotions: Emotive lexis in research articles. In: D. Gabryś-Barker and J. Bielska (eds.), The Affective Dimension in Second Language Acquisition, Bristol, Buffalo and Toronto: Multilingual Matters, 194210.

Łyda, A. (2014) Reflections on Academic Discourse: Studies in Academic English Lexis. Katowice: Uniwersytet Śląski.

Martin, J. R. (1995). Reading positions/positioning readers: judgement in English. Prospect: A Journal of Australian TESOL, 10, 27-37.

Martin, J. R. and P. White (2005). The Language of Evaluation: Appraisal in English. London and New York: Palgrave Macmillan. 
Myers, G. (2003). Discourse studies of scientific popularization: questioning the boundaries. Discourse Studies, 5(2), 265-279.

Nostrand, H. L. (1989). Authentic texts and cultural authenticity: An editorial. The Modern Language Journal, 73(1), 49-52.

Plutchik, R. (2001). The Nature of Emotions. (10 September 2013) <http:// americanscientist.org /articles/01articles/Plutchik.html>.

Plutchik, R. and H. R. Conte (1997). Circumplex Models of Personality and Emotions. Washington, DC: American Psychological Association.

Precht, K. (2000). Patterns of Stance in English. Unpublished PhD dissertation. University of Northern Arizona.

Sager, J. C. D. Dungworth and P. F. McDonald (1980). English Special Languages. Wiesbaden: Brandstetter.

Thaiss, C. and T. Myers Zawacki (2006). Engaged Writers, Dynamic Disciplines: Research on the Academic Writing Life. Portsmouth: Boynton and Cook. 